\title{
Pan-Atlantic distribution patterns and reproductive biology of the bigeye thresher, Alopias superciliosus
}

\author{
Joana Fernandez-Carvalho $\cdot$ Rui Coelho $(\mathbb{D} \cdot$ Jaime Mejuto $\cdot$ \\ Enric Cortés - Andrés Domingo - Kotaro Yokawa - Kwang-Ming Liu • \\ Blanca García-Cortés · Rodrigo Forselledo • Seiji Ohshimo • \\ Ana Ramos-Cartelle $\cdot$ Wen-Pei Tsai $\cdot$ Miguel N. Santos
}

Received: 9 November 2014/ Accepted: 19 May 2015

(C) Springer International Publishing Switzerland 2015

\begin{abstract}
The bigeye thresher (Alopias supercilious) is occasionally caught as bycatch in pelagic longline fisheries targeting tunas and swordfish. Still, it is one of the least known and studied of all pelagic sharks, which hinders assessment of the status of its populations. As part of an ongoing cooperative program for fisheries and biological data collection, information collected by fishery observers and through scientific projects from several nations that undertake fishing activities in the Atlantic (Japan, Portugal, Spain,
\end{abstract}

Electronic supplementary material The online version of this article (doi:10.1007/s11160-015-9389-7) contains supplementary material, which is available to authorized users.

J. Fernandez-Carvalho $\cdot$ R. Coelho $(\square) \cdot$ M. N. Santos Portuguese Institute for the Ocean and Atmosphere (IPMA, I.P.), Avenida 5 de Outubro s/n, 8700-305 Olhão, Portugal

e-mail: rpcoelho@ipma.pt

J. Fernandez-Carvalho $\cdot$ R. Coelho

Centre of Marine Sciences of Algarve (CCMAR),

University of Algarve, FCT Ed. 7, Campus de Gambelas, 8005-139 Faro, Portugal

J. Mejuto · B. García-Cortés · A. Ramos-Cartelle Instituto Español de Oceanografía (IEO), P.O. Box 130, 15080 A Coruña, Spain

E. Cortés

Panama City Laboratory, Southeast Fisheries Science Center, National Marine Fisheries Service, National Oceanographic and Atmospheric Administration (NOAANMFS), Panama City, FL 32408, USA
Taiwan, Uruguay and US) was compiled and analyzed. Datasets include information on location, size, sex and, in some cases, maturity stage. A total of 5590 bigeye thresher records collected between 1992 and 2013 were compiled, with sizes ranging from 70 to $305 \mathrm{~cm}$ fork length (FL). Considerable variability was observed in size, with tropical regions recording a smaller mean size compared to other regions. The distribution of juvenile and adult specimens also showed considerable variability, and the sex ratios varied between regions and size classes. Median sizes at maturity were estimated at $208.6 \mathrm{~cm}$ FL for females and $159.2 \mathrm{~cm}$ FL for males. Pregnant females were

\footnotetext{
A. Domingo $\cdot$ R. Forselledo

Laboratorio de Recursos Pelágicos, Dirección Nacional de Recursos Acuáticos (DINARA), CP 11200 Montevideo, Uruguay

\section{K. Yokawa $\cdot$ S. Ohshimo}

National Research Institute of Far Seas Fisheries (NRIFSF), 5-7-1 Orido, Shimizu-ku, Shizuoka-City, Shizuoka 424-8633, Japan

K.-M. Liu

Institute of Marine Affairs and Resource Management, National Taiwan Ocean University, Keelung 202, Taiwan

W.-P. Tsai

Department of Fisheries Production and Management, National Kaohsiung Marine University, Kaohsiung 811, Taiwan
} 
recorded in the tropical northeast and southwest Atlantic, with these regions possibly serving as nursery areas. The biological and distributional patterns presented in this study provide a better understanding of different aspects of this species in the Atlantic, which can help managers adopt more informed and efficient conservation measures.

Keywords Alopiidae $\cdot$ Pelagic sharks · Seasonality · Sex ratios $\cdot$ Size distribution $\cdot$ Spatial distribution

\section{Introduction}

The bigeye thresher (Alopias superciliosus) is a large epipelagic and mesopelagic species, occurring circumglobally in tropical and subtropical waters of the Atlantic, Indian and Pacific Oceans (Compagno 2001). Together with two other species, it belongs to the Alopiidae family (sea foxes) and Lamniformes order, and is characterized by having a remarkably long caudal fin. Thresher sharks have an aplacental viviparous reproductive mode with oophagy, characterized by the developing embryos being nourished by yolk-filled egg capsules that are continuously produced and deposited in the uteri (Gruber and Compagno 1981; Moreno and Morón 1992; Gilmore 1993; Conrath 2004). Similarly to the common thresher (Alopias vulpinus) and pelagic thresher (Alopias pelagicus), the litter size of the bigeye thresher is commonly two (rarely four) pups, though they grow more slowly and reach maturity at a later age than the other threshers (Moreno and Morón 1992; Mancini and Amorim 2006; Romero-Caicedo 2007; Smith et al. 2008a). In addition, though the bigeye thresher typically occurs in temperate and tropical waters, they can endure colder water and remain longer at deeper waters than many other pelagic sharks (Gruber and Compagno 1981; Smith et al. 2008a; IPMA, unpublished data).

Open ocean sharks are one of the least-studied groups of large vertebrates, as the study of wideranging and highly migratory fishes that spend most of their lives far from land poses particular difficulties (Pikitch et al. 2008). In the last decade, knowledge on the biology, life history, migrations, behavior and environmental preferences of these species has improved (Pikitch et al. 2008). However, more research is needed for a better assessment of the impact of fisheries on populations and to facilitate effective management plans for these highly migratory shark species (Camhi et al. 2008a; ICCAT 2013). Due to the shortage of long time series of information (e.g. catches, fishing effort, changes in abundance) on most pelagic shark populations to conduct stock assessments, demographic models are often chosen to provide initial information and prioritize species for research (Simpfendorfer 2004). Demographic models rely primarily on life history parameters (i.e. age of sexual maturity, litter size, maximum reproductive age, instantaneous rate of natural mortality); thus obtaining this type of biological data is essential to estimate species vulnerability in ecological risk assessments (ERAs) or for conducting fisheries stock assessments (Camhi et al. 2008b; Cortés et al. 2010).

Despite being caught as bycatch in several pelagic fisheries, little biological information is available for the bigeye thresher in the Atlantic Ocean, probably because of their relatively low occurrence in surface longline catches (Mejuto and Garcés 1984; Mejuto 1985; Castro et al. 2000; Berrondo et al. 2007; Mejuto et al. 2009), estimated at ca. $0.2 \%$ of the total shark bycatch (Mejuto et al. 2009). Some reproductive parameters have been reported for the Atlantic (Stillwell and Casey 1976; Gruber and Compagno 1981; Moreno and Morón 1992; Gilmore 1993; Amorim et al. 1998) in general using small datasets. The only extensive reproductive study available for the species is from the Northwest Pacific Ocean (Chen et al. 1997).

When reviewing the demography of pelagic shark species, several authors ranked the bigeye thresher among the least productive species, highlighting its vulnerability to fisheries impacts (Chen and Yuan 2006; Cortés 2008; Smith et al. 2008b). In addition, an ERA of pelagic sharks caught in Atlantic pelagic longlines placed the bigeye thresher at high risk, highlighting the urgent need for better basic biological information on this species (Cortés et al. 2010). Some countries, at the national level first, and more recently under the purview of the International Commission for the Conservation of Atlantic Tunas (ICCAT), which is responsible for the management of this species in the Atlantic, have prohibited the retention and sale of bigeye thresher sharks caught in the fisheries they manage. Further, it is recommended to release live specimens when accidentally captured, and there are 
requirements that both incidental catches and live releases be recorded in accordance with ICCAT data reporting requirements (ICCAT Recommendation 2009/07). Other tuna Regional Fisheries Management Organizations (tRFMOs), such as the Indian Ocean Tuna Commission (IOTC), have similar management measures for this species (IOTC Resolution 12/09). Despite this, as shown by Coelho et al. (2012), the hooking mortality of bigeye threshers seems to be high (ca. $51 \%$ ) in some pelagic surface longline fisheries, and simply releasing the caught specimens may not be an adequate conservation strategy, as the majority of animals are captured and discarded already dead. However, it is possible that this high at-haulback hooking mortality is caused by other factors, such as fishing procedures and gear configuration, including length and material of branch line, main line, and shortening ratios (Mizuno et al. 1998). The International Union for the Conservation of Nature (IUCN) Shark Specialist Group classifies the bigeye thresher as "Vulnerable" globally according to the IUCN Red List Criteria and "Endangered" in the Northwest Atlantic and Western central Atlantic (Amorim et al. 2009).

To improve the limited information available for this species in the Atlantic, the main objectives of this study were to provide information on the distributional patterns of the bigeye thresher caught by pelagic longlines targeting mainly tunas or swordfish in the Atlantic Ocean. This was particularly in terms of sizes, sex ratios and proportions of juvenile and adult specimens, as well as median size at maturity and litter size. These results can be used to better evaluate the status and manage this species in the Atlantic Ocean.

\section{Materials and methods}

\section{Data collection}

Bigeye thresher observations were made within the scope of national observer programs or scientific projects. Fishery observers from IPMA (Portuguese Institute for the Ocean and Atmosphere), NOAA/ NMFS (National Marine Fisheries Service), DINARA (Dirección Nacional de Recursos Acuáticos), NRIFSF (National Research Institute of Far Seas Fisheries), Taiwan Fisheries Agency, and scientific projects of
IEO (Instituto Español de Oceanografía) collected the data onboard Portuguese, US, Uruguayan, Japanese, Taiwanese and Spanish commercial longline vessels, respectively, targeting tunas or swordfish in the Atlantic Ocean. Data on bigeye thresher sizes by sex were available starting in 1992 for the US, 1993 for Spain, 1997 for Japan, 2003 for Portugal and Uruguay, and 2004 for Taiwan. US and Uruguayan data were available up to 2010, Portuguese, Japanese and Taiwanese data up to 2012, and Spanish data up to 2013. The spatial effort distribution for these fleets was expressed as the total number of hooks in $5^{\circ} \times 5^{\circ}$ resolution grids using the ICCAT effort distribution (EffDIS) database (Palma and Gallego 2010). Only the years for which bigeye thresher data were available for each fleet were considered, noting that the current ICCAT EffDIS database only has data until 2009.

Data were collected across a wide geographical range. For analysis purposes, the two hemispheres were separated based on the $5^{\circ} \mathrm{N}$ parallel, as recommended in the ICCAT Manual for shark species (ICCAT 2006-2009). Furthermore, the region was divided into six major areas taking into consideration not only the ICCAT sampling areas for sharks (ICCAT 2006-2009), but also the areas of operation and fishing grounds of these pelagic longline fleets in the Atlantic Ocean. These areas were assigned as follows: Northwest-north of $24^{\circ} \mathrm{N}$ and west of $40^{\circ} \mathrm{W}$; Northeastnorth of $24^{\circ} \mathrm{N}$ and east of $40^{\circ} \mathrm{W}$; Tropical Northbetween $5^{\circ} \mathrm{N}$ and $24^{\circ} \mathrm{N}$; Equatorial-between $5^{\circ} \mathrm{N}$ and $5^{\circ} \mathrm{S}$; Southwest-south of $5^{\circ} \mathrm{S}$ and west of $20^{\circ} \mathrm{W}$; Southeast—south of $5^{\circ} \mathrm{S}$ and east of $20^{\circ} \mathrm{W}$ (Fig. 1).

For animals caught, fishery observers recorded data on specimen size, sex, capture location and date. Additionally, in the Portuguese program, maturity stage was also assessed and recorded whenever a dead specimen was captured while retrieving the longline, and in the Spanish, Portuguese and Uruguayan fleets observers recorded, when possible, the presence of pregnant females and characteristics of the embryos. Fork length (FL) was measured in all cases, except in the Japanese and Taiwanese programs, where precaudal length and total length (TL), respectively, were measured. In these cases, sizes were converted to fork length (FL) using the equations proposed by Liu et al. (1998). For the Portuguese Program the size of the claspers of males was measured and the maturity stage determined qualitatively, whenever possible. Specimens were classified as mature and immature based on 
Fig. 1 Location and sizes (fork length, FL in $\mathrm{cm}$ ) of bigeye thresher (Alopias superciliosus) recorded in the six sampling regions of this study. The gray scale of the dots represents specimen sizes, with darker colors representing smaller specimens and lighter colors larger specimens. The categorization of size classes for the map was carried out using the 20th percentiles of the size data. The location of pregnant females recorded by the Spanish, Portuguese and Uruguayan fleets during this study is represented with diamond symbols

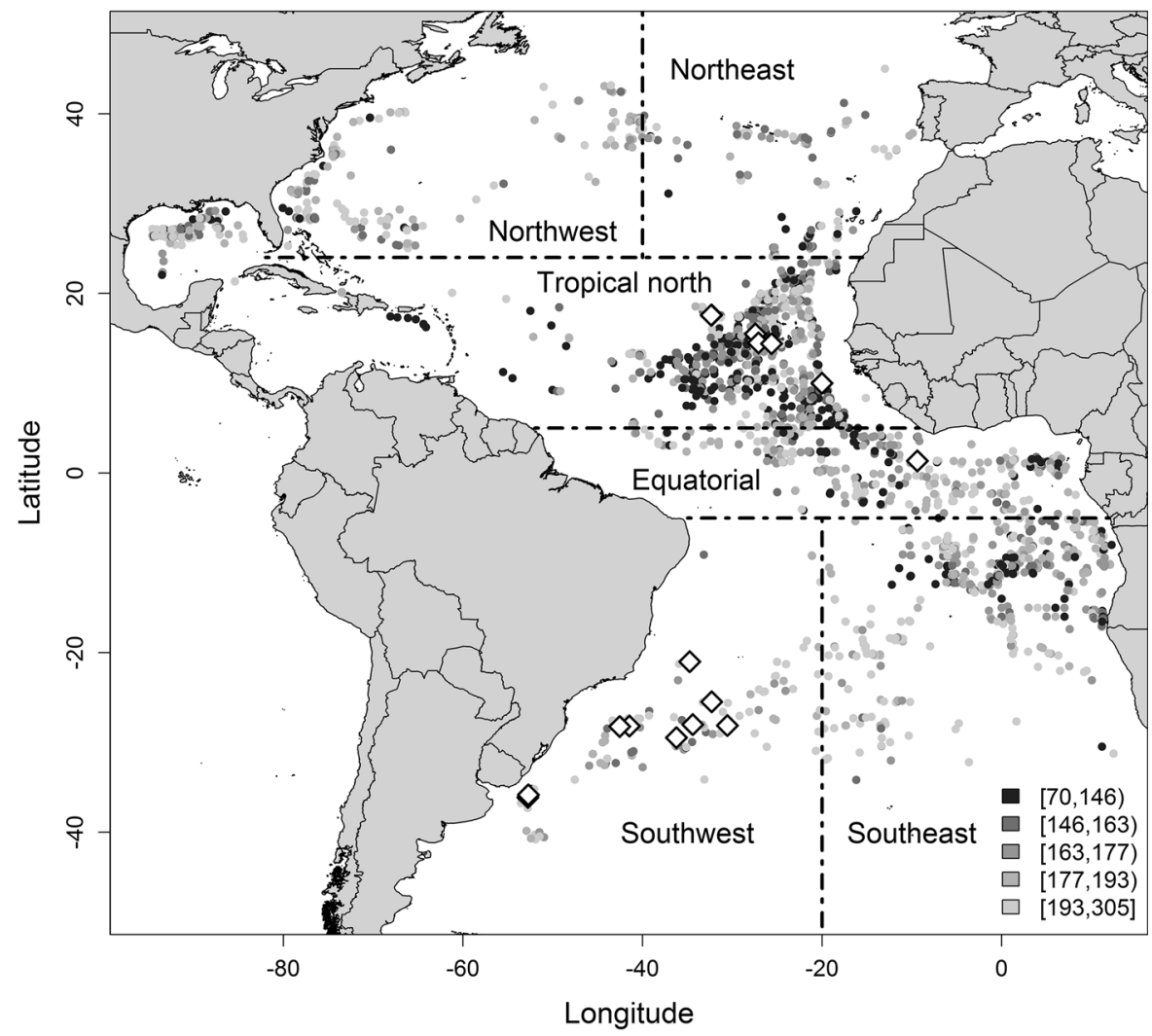

the scale proposed by Stehmann (2002): for males, stages 1 (immature) and 2 (maturing) were considered immature while stages 3 (mature) and 4 (active) were considered mature. For females, stages 1 (immature) and 2 (maturing) were considered immature, while stages 3 (mature), 4 (developing), 5 (differentiating), 6 (expecting) and 7 (post-natal/resting) were considered mature (see table in Online Resource 1).

Data analysis

Size data were tested for normality with KolmogorovSmirnov normality tests with the Lilliefors correction (Lilliefors 1967), and for homogeneity of variances with Levene tests (Levene 1960). Given the lack of normality of data and homogeneity of variances even after transforming the data with square-root and $\log$ functions, specimen sizes were compared among regions, sexes and quarters of the year using nonparametric Kruskal-Wallis tests, and $k$-sample permutation tests using the permutational central limit theorem (Manly 2007). In the cases for which statistical differences were detected, multiple pairwise comparison tests were carried out to detect between which categories the differences were significant (Siegel and Castellan 1988).

Sex ratios were calculated and compared between regions with contingency tables and Pearson's Chisquared tests. Sex ratios were also compared between the seasons of the year and size classes (categorized with the 20th percentiles of the data) taking into account the various regions, using Cochran-MantelHaenszel (CMH) Chi-squared tests (Cochran 1954). This test allows detecting seasonality of size-related effects in the sex ratios conditional to each of the regions analyzed.

Maturity ogives were developed to estimate the median size at maturity $\left(\mathrm{L}_{50}\right)$, or length at which $50 \%$ of the sharks were mature, with the maturity stage data from the Portuguese observer program. For each sex, parameters, standard errors, and $95 \%$ confidence intervals (CIs) were estimated. The maturity ogives were fitted by non-linear least-squares (NLS) regression, using the equation: 


$$
P_{L i}=\frac{1}{1+e^{-b\left(L_{i}-L_{50}\right)}}
$$

where $P_{L i}$ is the proportion of mature individuals in size class $\mathrm{L}_{i}$ (using $5 \mathrm{~cm}$ FL size classes), $b$ is the slope and $L_{50}$ is the size at which $50 \%$ of individuals mature. Maturity ogives were fitted for each sex separately and $\mathrm{L}_{50}$ estimates were compared between sexes by analyzing overlaps in the $95 \%$ CIs.

The relationship between fork length (FL) and clasper length (CL) was also analyzed using a linear regression model. In addition, a segmented regression model (SRM) was used to estimate the transition points and slopes in the regression between fork length and clasper length. These breakpoints have been defined to identify the three FL intervals with different slopes that represent the three maturity stages of male elasmobranchs: "immature", "maturing" and "mature" (Segura et al. 2013). Thus, the breakpoints are defined as the values of the explanatory variable (FL) at which the changes in slope occur (Muggeo 2003). Standard errors were calculated for all the estimated parameters and the coefficients of determination were calculated to test the goodness-of-fit. Furthermore, to assess model adequacy to the data, the Akaike information criterion value (AIC, Akaike 1973) was calculated for both models (linear regression and SRM).

A logistic-binomial generalized linear model (GLM) was specified to determine the influence of each region, sex and quarter of the year on the oddsratios of capturing juvenile specimens, considering the estimated median sizes-at-maturity. The significance of the model parameters was tested with Wald statistics and likelihood ratio tests comparing nested models. Model goodness-of-fit was assessed with the Nagelkerke coefficient of determination $\left(\mathrm{R}^{2}\right.$, Nagelkerke 1991). The discriminative capacity of the models was determined by the area under the curve (AUC) of the receiver operating characteristic curves (Fawcett 2006), with the calculation of the model sensitivity (capacity to correctly detect the event, in this case defined as the capture of juveniles) and model specificity (capacity to correctly exclude the nonevents, in this case the capture of adults). Cross validation was carried out using a $k$-fold cross validation procedure (with $k=10$ ) to estimate the expected level of fit of the models to new data, and to assess eventual over-fitting problems (Fushiki 2011).
Because the models in this study are binomial, the cross validation procedure was used to estimate the misclassification error rate. The odds-ratios of the parameters, with their respective $90 \%$ CIs, were calculated and used for model interpretation. The equatorial region and quarter 1 were used as the baseline parameters, and the odds-ratios calculated comparatively for the other regions and quarters of the year, taking into account their interaction effects.

Analysis for this paper was carried out using the $\mathrm{R}$ language for statistical computing ( $\mathrm{R}$ Core Team 2013). Besides the $R$ core program functions, some additional libraries were used, specifically "segmented" for the SRM models (Muggeo 2003), "gmodels" for the contingency table analysis (Warnes et al. 2012), "ggplot2" for the graphical analysis (Wickham 2009), and "maps" (Becker et al. 2013), "maptools" (Bivand and Lewin-Koh 2013) and "mapplots" (Gerritsen 2013) for the maps.

\section{Results}

Size distribution

A total of 5590 bigeye thresher specimens were recorded within the scope of this study (2547 from the Spanish fleet, 1219 from the Taiwanese fleet, 1211 from Portuguese fleet, 426 from the US fleet, 134 from the Japanese fleet and 53 from the Uruguayan fleet). The specimens ranged in size from 70 to $305 \mathrm{~cm}$ FL (70-300 cm FL for females and 75-305 cm FL for males), covering most of the known size range of the species. The sample was composed mostly of specimens captured in the tropical north $(38.9 \%)$ and southeast regions $(36.4 \%)$, followed by $9.1 \%$ in the northwest, $9.1 \%$ in the equatorial, $4.0 \%$ in the northeast and $2.5 \%$ in the southwest regions (Fig. 1). The spatial distribution of the effort of these fleets during the years for which data were available also covered a wide geographical area over the entire Atlantic Ocean. However, some areas had more effort, specifically along the temperate, tropical and equatorial eastern Atlantic, and also in some areas of the northwest Atlantic (see figure in Online Resource 2).

Considerable variability was observed in the size distribution of males and females among the Atlantic regions. The larger-sized specimens tended to be captured mainly in the higher latitudes, predominantly 


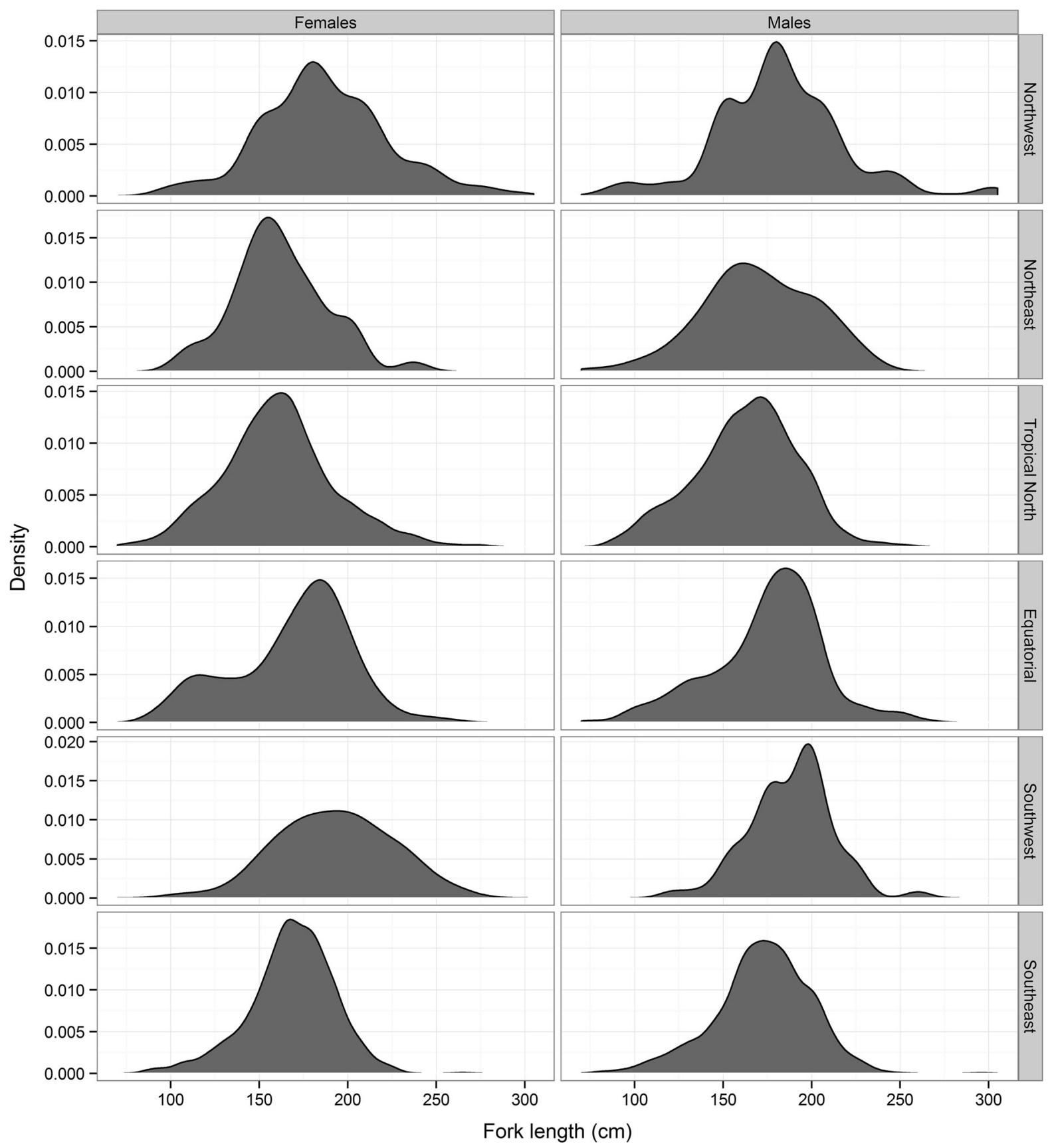

Fig. 2 Length-frequency distributions of male and female bigeye thresher (A. superciliosus) caught in six sampling regions of the Atlantic Ocean

in the northwest and southwest Atlantic, while smaller specimens tended to be captured mainly in the tropical north and northeast areas (Fig. 2). It was also noteworthy that a very low prevalence of the smaller sized specimens $(<150 \mathrm{~cm}$ FL) was recorded in all regions (Fig. 2). These regional trends tended to be common for both males and females, even though some differences between sexes were detected. In general, in the higher northern and southern latitudes males tended to be larger than females in the eastern 
regions (northeast and southeast), while females tended to be larger in the western regions (southwest and northwest) (Fig. 2). In the equatorial area and tropical north, males also tended to be larger than females (Fig. 2).

Seasonality also seemed to influence the size of captured bigeye threshers. In the northern regions an opposite trend was observed when comparing the northwest and northeast, with sizes tending to increase throughout the year in the northwest and decrease in the northeast, both with similar size ranges except for the 4th quarter in the northeast where the sizes were much smaller (Fig. 3). In the southeast and southwest regions smaller specimens were caught in the 2nd and 3 rd quarters and larger ones in the 1 st and 4 th quarters (Fig. 3). In the tropical north the sizes were much smaller and tended to be relatively similar along the year (with even smaller sizes in the 3rd quarter), while in the equatorial region there was a tendency for increasing sizes along the year (Fig. 3).

Size data were not normally distributed (Lilliefors test: $\mathrm{D}=0.042, p$ value $<0.001)$ and the variances were heterogeneous between regions (Levene test: $\mathrm{F}=15.01, d f=5, p$ value $<0.001)$ and quarters (Levene test: $\mathrm{F}=24.71, d f=3, p$ value $<0.001$ ), and homogeneous between sexes (Levene test: $\mathrm{F}=0.61$, $d f=1, p$ value $=0.4358$ ). Using univariate nonparametric statistical tests revealed that sizes were significantly different between regions $(\mathrm{K}-\mathrm{W}$ : Chisquared $=333.98, d f=5, p$ value $<0.001$; permutation test: Chi-squared $=334.14, d f=5, p$ value $<0.001)$ and between sexes (K-W: Chisquared $=23.86, d f=1, p$ value $<0.001$; permutation test: Chi-squared $=13.46, d f=1, p$ value $<0.001)$, but not between quarters of the year $(\mathrm{K}-$ $\mathrm{W}$ : Chi-squared $=5.35, d f=3, p$ value $=0.148$; permutation test: Chi-squared $=4.87, \quad d f=3$, $p$ value $=0.181)$.

\section{Sex ratios}

Of the total bigeye threshers recorded, 2664 (47.7\%) were females and the remaining 2926 (52.3\%) were males, with some local variability recorded in the sex

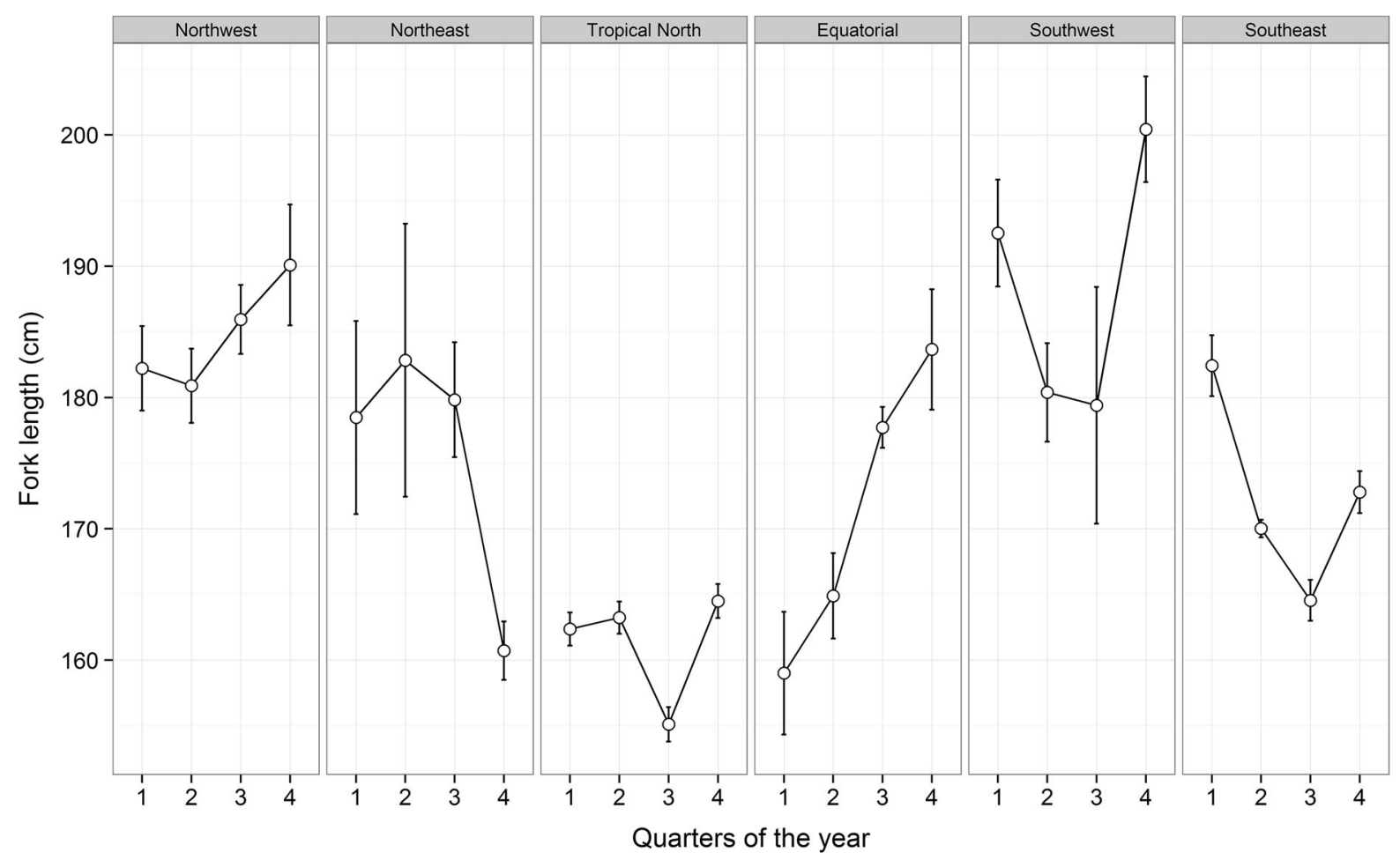

Fig. 3 Mean size of bigeye thresher (A. superciliosus) caught in six sampling regions of the Atlantic Ocean during four quarters of the year. The error bars are \pm 1 standard error 
Fig. 4 Map of the bigeye thresher (A. superciliosus) sex-ratios recorded in $5^{\circ} \times 5^{\circ}$ squares during this study. The circle sizes are proportional to the sample size $(\mathrm{N})$ in each square

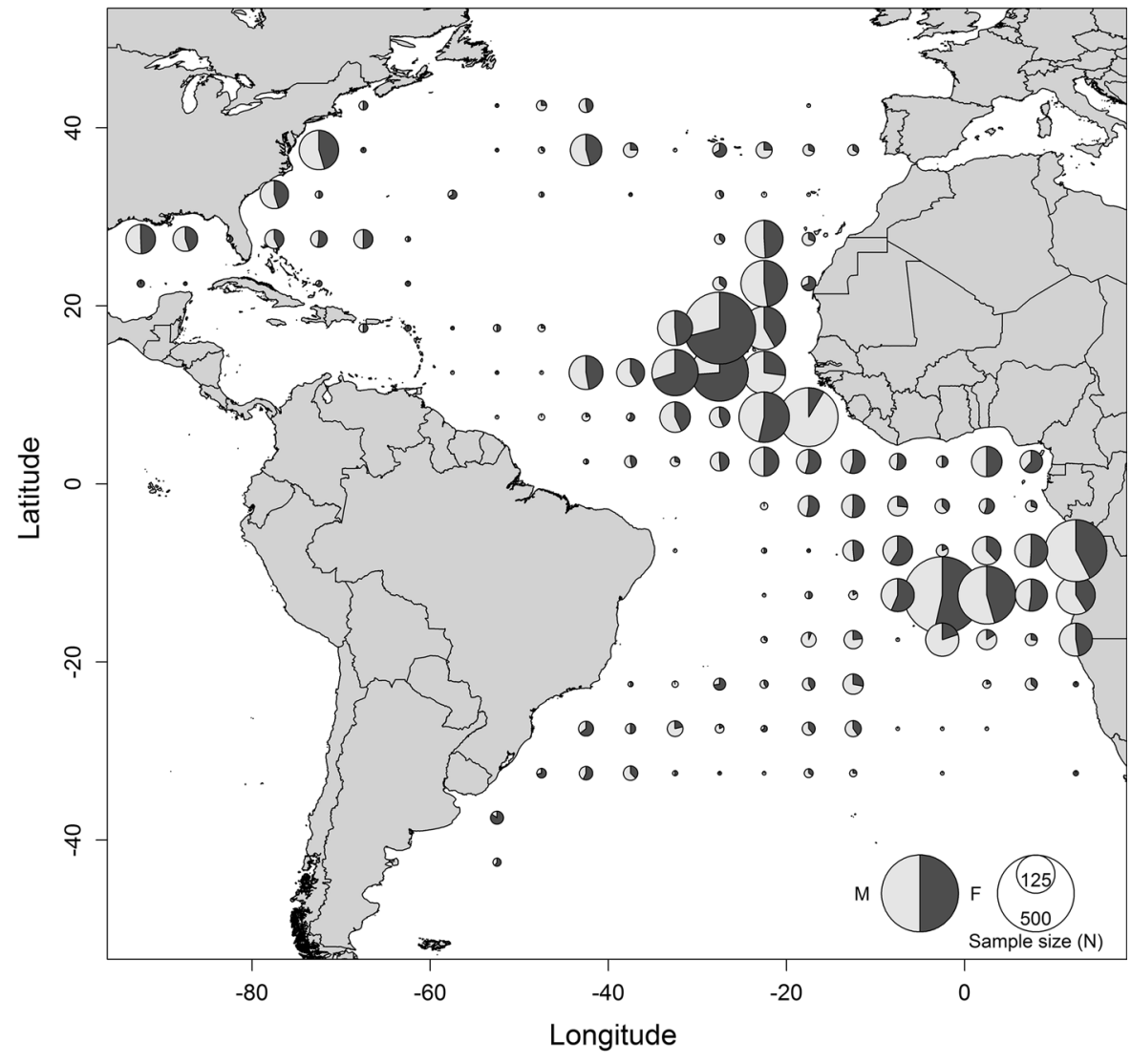

ratios (Fig. 4). Particularly, there seemed to be some evidence of the presence of more males in coastal waters off central Africa and in oceanic South Atlantic waters, while around some islands, such as in the Cape Verde archipelago, the sex ratio was highly biased towards the presence of more females (Fig. 4).

When comparing the major regions defined in this study there were significant differences in the overall sex ratios (proportion test: Chi-squared: $16.34, d f=5$, $p$ value $=0.006$ ), with most regions having a higher proportion of males, particularly in the northwest, northeast and southeast, while in the tropical north there was a slightly higher proportion of females. There were also significant differences in sex ratios among seasons when compared conditionally within the different regions $(\mathrm{CMH}$ test: Chisquared $=13.03, d f=3, p$ value $=0.005)$. While females tended to be less frequent than males for all regions and seasons, a higher proportion of females were observed during the 2 nd quarter of the year in the northeast and during the 3rd quarter in the southwest.
In contrast, a much lower proportion of females were observed in the 2nd quarter in the tropical north compared to a generally higher proportion of females in this region throughout the rest of the year (Fig. 5a). In the equatorial region the sex ratios remained relatively constant throughout the year with values of approximately $50 \%$ for each sex (Fig. 5a).

Significant differences were also detected in the sex ratios among sizes tested conditionally within the different regions $(\mathrm{CMH}$ test: Chi-squared $=22.03$, $d f=4, p$ value $<0.001$ ). A higher proportion of males were observed in the larger size classes in the northeast, southeast and equatorial regions; in the northwest there was a slight tendency for a higher proportion of females in the larger size classes, and in the tropical north and southwest there were more females in both the smaller and larger size classes (Fig. 5b). In the tropical north and southwest there were higher proportions of females both in the smaller and larger size classes, and more males in the middle sizes (Fig. 5b). The differences obtained in the overall 

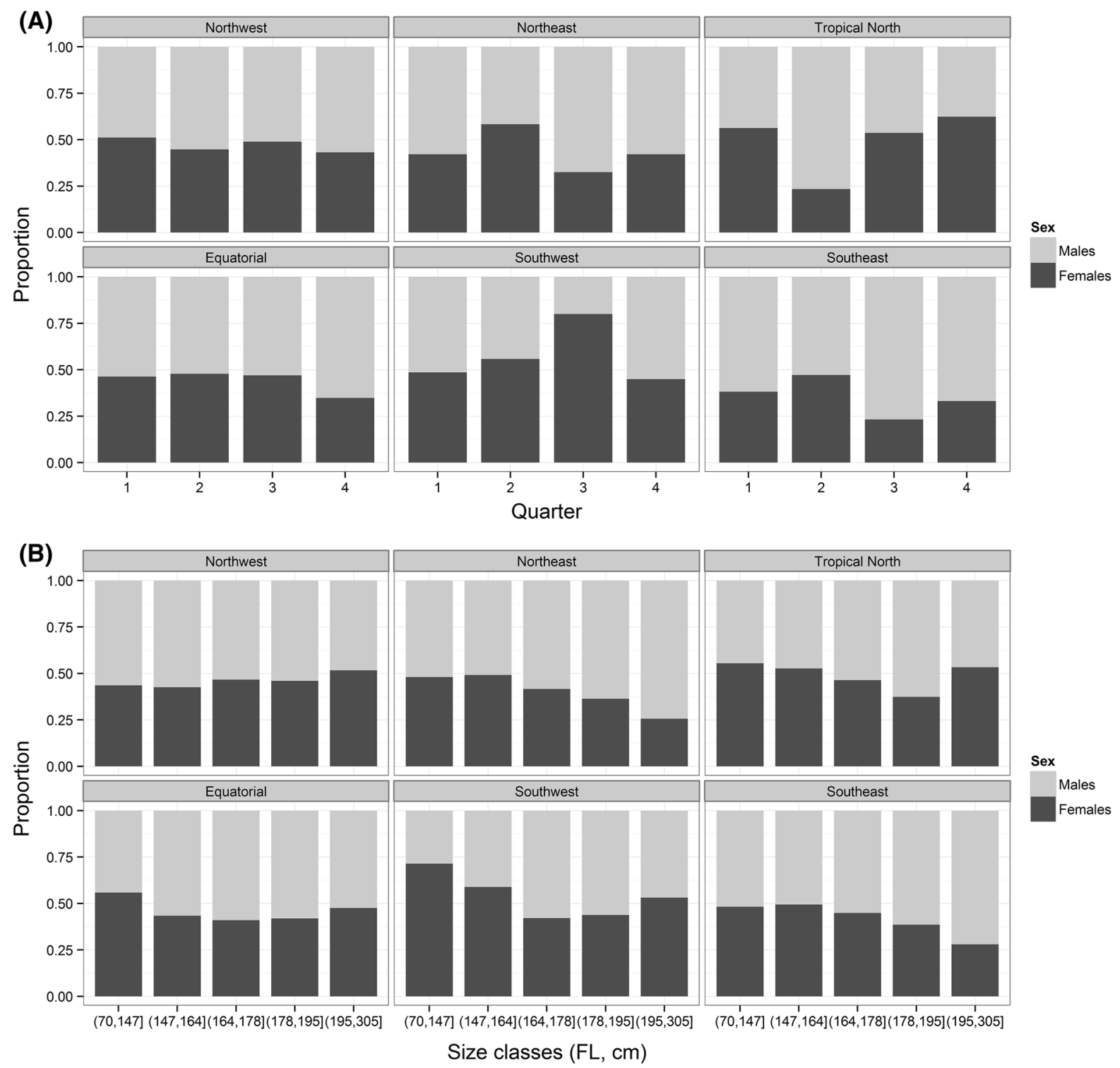

Fig. 5 Sex ratios of bigeye thresher (A. superciliosus) in the six regions of the Atlantic considered for this study, per quarter of the year (a) and per size class (b). The categorization of size classes was carried out using the 20th percentiles of the size data

sex ratios among regions could be caused by the size segregation of individuals in those regions.

Median size at maturity

Maturity information was available for 642 specimens, from which 257 were females (232 immature and 25 mature) and 385 were males (157 immature and 228 mature) (Table 1). Sample size of mature females was thus low. For this reason, maturity ogives and the clasper length versus FL relationship were calculated using combined data from all regions.

Estimated maturity ogives were (Fig. 6a):

$P L i=\frac{1}{1+e^{-0.06(L i-208.64)}} \quad$ for females

and

$P L i=\frac{1}{1+e^{-0.07(L i-159.24)}} \quad$ for males. 
Table 1 Bigeye thresher (A. superciliosus) observed size ranges and estimated length at $50 \%$ maturity $\left(\mathrm{L}_{50}\right)$ with $95 \%$ confidence intervals for males and females obtained in this study

\begin{tabular}{|c|c|c|c|c|c|c|c|c|}
\hline \multirow[t]{2}{*}{ Sex } & \multicolumn{4}{|c|}{ Size range (cm FL) } & \multirow[t]{2}{*}{$\mathrm{L}_{50}(\mathrm{~cm})$} & \multicolumn{2}{|c|}{$95 \% \mathrm{CI}$} & \multirow[t]{2}{*}{$\mathrm{L}_{50} / \mathrm{L}$} \\
\hline & Immature & $\mathrm{n}$ & Mature & $\mathrm{n}$ & & LCL & UCL & \\
\hline Females & $100-220$ & 232 & $140-264$ & 25 & 208.6 & 204.8 & 212.9 & 0.79 \\
\hline Males & $90-203$ & 157 & $130-260$ & 228 & 159.2 & 156.5 & 162.0 & 0.61 \\
\hline
\end{tabular}

$L C L$ is lower confidence limit, $U C L$ is upper confidence limit

Fig. 6 Maturity ogives for male and female bigeye thresher (A. superciliosus) with the mature:immature ratio by size class (a), and segmented regression model between fork length (FL) and clasper length for male bigeye threshers (b), fitted with the sizes grouped into $5 \mathrm{~cm}$ classes. In the segmented model the dotdash lines represent the estimated breakpoints and the associated dashed lines their $95 \%$ confidence intervals
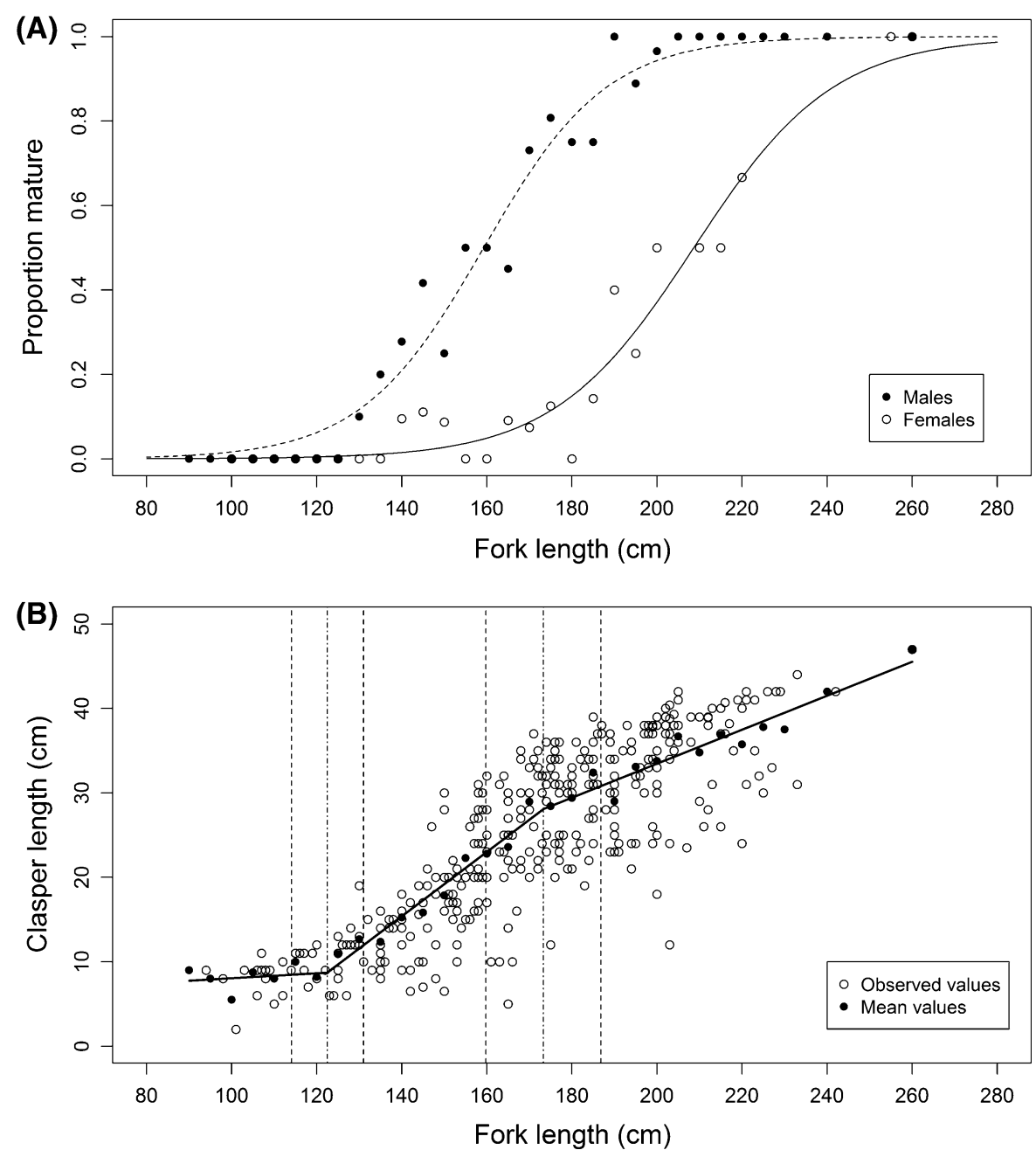

Female bigeye threshers mature at larger sizes than males (Table 1). Differences between sexes were significant as the $95 \%$ CIs of $\mathrm{L}_{50}$ do not overlap. Both sexes are late maturing, with females maturing at $208.63 \mathrm{~cm}$ FL (79 \% of the maximum observed size) and males at
$159.24 \mathrm{~cm}$ FL (61 \% of the maximum observed size). The largest immature female was $220 \mathrm{~cm}$ FL, while the smallest mature female was $140 \mathrm{~cm}$ FL. For males, the largest immature specimen was $203 \mathrm{~cm} \mathrm{FL}$, while the smallest mature specimen was $130 \mathrm{~cm}$ FL. 
The claspers of 372 male specimens were measured and their lengths were plotted against FL (Fig. 6b). A linear regression fitted the FL versus clasper length data well $\left(\mathrm{CL}=0.26 \quad \mathrm{FL}-18.97 ; \mathrm{r}^{2}=0.96, \quad \mathrm{AIC}=\right.$ 143.38), but the SRM had an even higher coefficient of determination and lower value of AIC $\left(\mathrm{r}^{2}=0.99\right.$, $\mathrm{AIC}=118.25$ ), indicating a better goodness-of-fit to the data than the linear regression. Two breakpoints were estimated for bigeye thresher males with the SRM, resulting in three linear phases such that:

$$
\begin{aligned}
& \text { 1. } \mathrm{CL}=0.03 \mathrm{FL}+5.06, \text { if } \mathrm{FL}<122.5 \mathrm{~cm} \\
& \text { 2. } \mathrm{CL}=0.38 \quad \mathrm{FL}-37.97, \quad \text { if } 122.5 \leq \mathrm{FL} \leq \\
& 173.3 \mathrm{~cm} \\
& \text { 3. } \mathrm{CL}=0.2 \mathrm{FL}-6.78, \text { if } \mathrm{FL}>173.3 \mathrm{~cm}
\end{aligned}
$$

These three linear phases represent the successive maturity stages effectively modeled by the SRM. Thus, phase 1 contains the immature sharks characterized by a subtle slope close to zero; phase 2 represents the transitional "maturing" stage with the steepest slope; and phase 3 presents a flatter slope containing only the mature specimens.

Litter size, embryonic development and presence of pregnant females

Overall, 14 pregnant females were recorded, plus two that showed signs of recent mating but still had no visible embryos in the uteri. Each of the pregnant females had two embryos, one in each of the uteri.

The occurrence of pregnant females was recorded mainly in two regions of the study area, specifically in the tropical northeast between $1-17^{\circ} \mathrm{N} / 9-32^{\circ} \mathrm{W}$, and in the southwest between $21-36^{\circ} \mathrm{S} / 30-52^{\circ} \mathrm{W}$ (Fig. 1). In the tropical northeast Atlantic, the smallest pregnant female recorded was $210 \mathrm{~cm}$ FL, the largest, $240 \mathrm{~cm}$ $\mathrm{FL}$, and the recorded embryos ranged in size between 26 and $90 \mathrm{~cm} \mathrm{FL.} \mathrm{In} \mathrm{the} \mathrm{southwest} \mathrm{Atlantic,} \mathrm{the}$ smallest pregnant female recorded was $209 \mathrm{~cm}$ FL, the largest, $256 \mathrm{~cm}$ FL, with the two females that showed recent signs of mating also recorded in this area measuring $207 \mathrm{~cm}$ FL. In the southwest Atlantic, the recorded embryos ranged in size between 4 and $73 \mathrm{~cm}$ FL, noting that the embryos measuring $4 \mathrm{~cm}$ were recorded in one female in the early pregnancy stages with the embryos still encapsulated, in a region closer to the Uruguayan coast. In terms of embryonic development throughout the year, the largest embryos were recorded in October-November in the tropical northeast Atlantic and in March in the southwest Atlantic. Embryos with both the largest and smallest sizes were observed in the southwest Atlantic in March.

Expected distribution of juveniles and adults

Considerable variability was observed in the distribution of juvenile and adult specimens, when considering sex, region, and season factors, but in general most regions and seasons tended to have a high proportion of juvenile females and adult males (Fig. 7).

The final estimated logistic-binomial GLM considered the factors sex (deviance explained $=2337.6$, $d f=1, \quad p$ value $<0.001$ ), region (deviance explained $=110.1, d f=5, p$ value $<0.001)$ and quarter (deviance explained $=5.6, d f=3, p$ value $=0.132$ ), and also the interaction between quarter and region (likelihood ratio test for nested models: deviance explained $=95.1, d f=15 ; p$ value $<0.001)$. Even though the variable quarter was not significant in terms of single effect, the presence of a significant interaction with region justified having this variable, as well as the interaction, in the model. In terms of goodness-of-fit, the final model had a Nagelkerke $\mathrm{R}^{2}$ of 0.538 and an AUC of 0.855 , with a sensitivity of $72.0 \%$ and a specificity of $90.1 \%$. The $k$-fold cross-validation procedure resulted in a predicted error for new data of $20.9 \%$.

Compared to the baseline combination (equatorial region and quarter 1), the odds of capturing juveniles increased in some area-season combinations, whereas they decreased in others. Specifically, the odds-ratios of capturing more juvenile specimens increased significantly in the northeast quarter 4 , tropical north quarters 2, 3 and 4, southwest quarters 2 and 3, and southeast quarters 2, 3 and 4 (Fig. 8). By contrast, the odds of capturing more juveniles decreased significantly in several regions earlier in the year, specifically in quarter 1 of the northeast, northwest, southwest and southeast, as well as in the equatorial region in quarters 2, 3 and 4 (Fig. 8). Additionally, the odds of capturing juvenile males were substantially lower (96.3, with $90 \%$ CI varying between 95.7 and $96.8 \%$ ) than the odds of capturing juvenile females.

\section{Discussion}

Considerable variability was observed in the distributional patterns and size distribution of bigeye threshers 


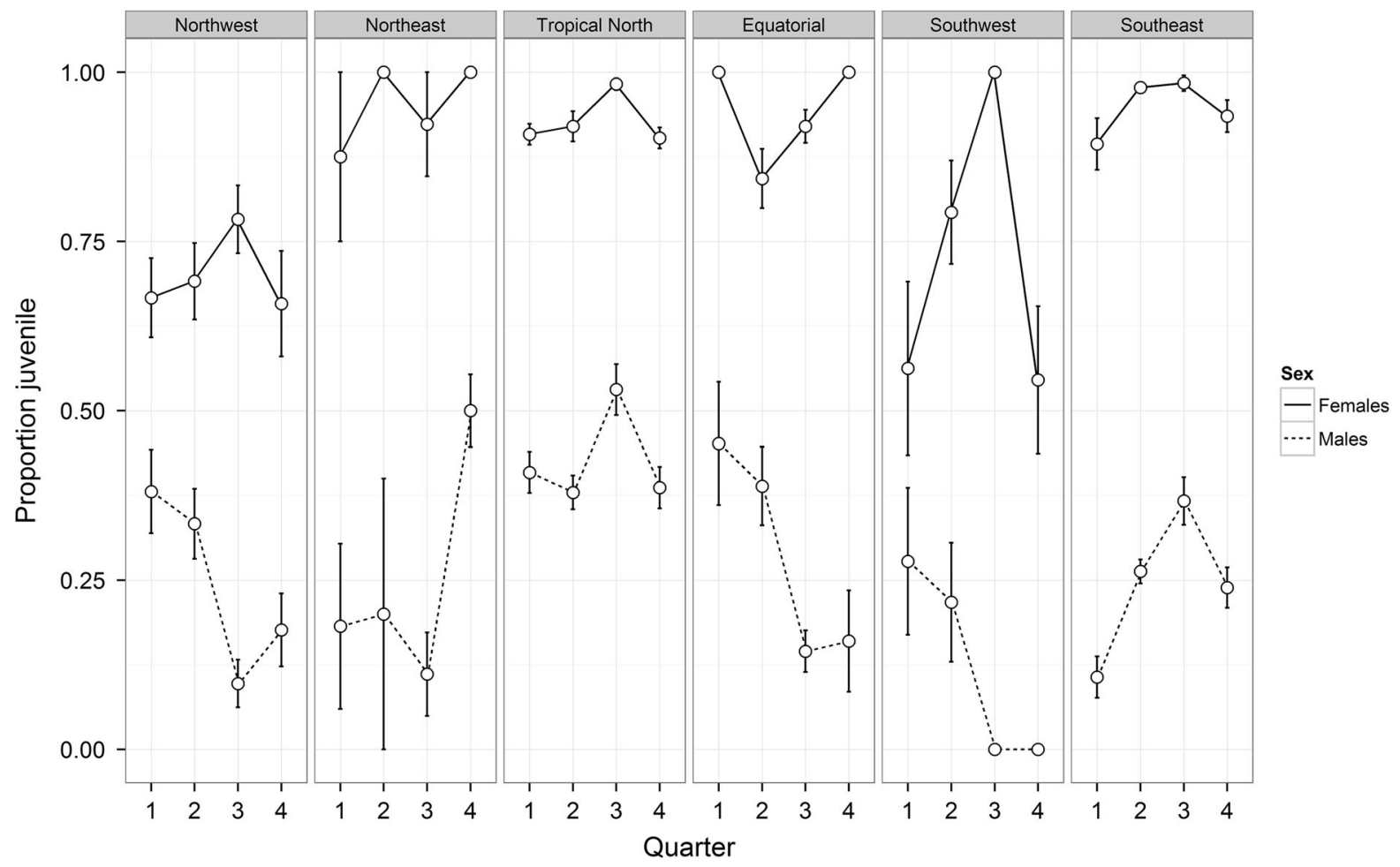

Fig. 7 Proportion of juvenile bigeye thresher (A. superciliosus) caught in the six sampling regions of the Atlantic Ocean in each quarter of the year. The error bars are \pm 1 standard error

along the Atlantic Ocean during the different seasons of the year. Particular emphasis is given to the tropical region where the mean sizes tended to be smaller than in the other Atlantic regions. Pregnant females found were recorded in the tropical northeast and southwest Atlantic, with these two regions possibly serving as nursery areas for this oceanic species.

Differences in the length-frequency distributions and proportions of juvenile and adult specimens were found among the regions of the Atlantic Ocean examined. The most significantly different region seemed to be the tropical north Atlantic, where specimens tended to be smaller and the proportion of juveniles (both males and females) higher throughout the entire year. It is possible that there are migratory and habitat segregation patterns by growth stages between the regions and seasons of the year, with smaller and younger sharks concentrating predominantly in the tropical northern region, while the larger adults prefer the temperate areas of the northern and southern Atlantic. This could be related to the migratory routes of this species in the Atlantic, with the smaller fish present mainly in the tropical north and then moving to the higher latitudes as they get larger and older. However, it is important to note that the data used in our study come from several different fleets, with different fishing métiers that target different species, and as such the size ranges and abundance reported by each fleet for each region are also affected by area availability and fleet selectivity. Additionally, the temporal overlap of the data from the several fleets analyzed is limited and may also contribute to some of the differences found. With regards to the spatial distribution of the data, and while the observations reported reflect in part the species spatial dynamics, there is also some influence from the sampling effort of each fleet, and therefore the reported data may not be entirely representative of the prevalence of the species at each location.

The maximum sizes observed in our sample of $305 \mathrm{~cm}$ FL for males and $300 \mathrm{~cm}$ FL for females $(504 \mathrm{~cm}$ TL for males and $496 \mathrm{~cm}$ TL for females, after conversion), were higher than those reported in the literature. For the northeast Atlantic $484 \mathrm{~cm}$ TL has 


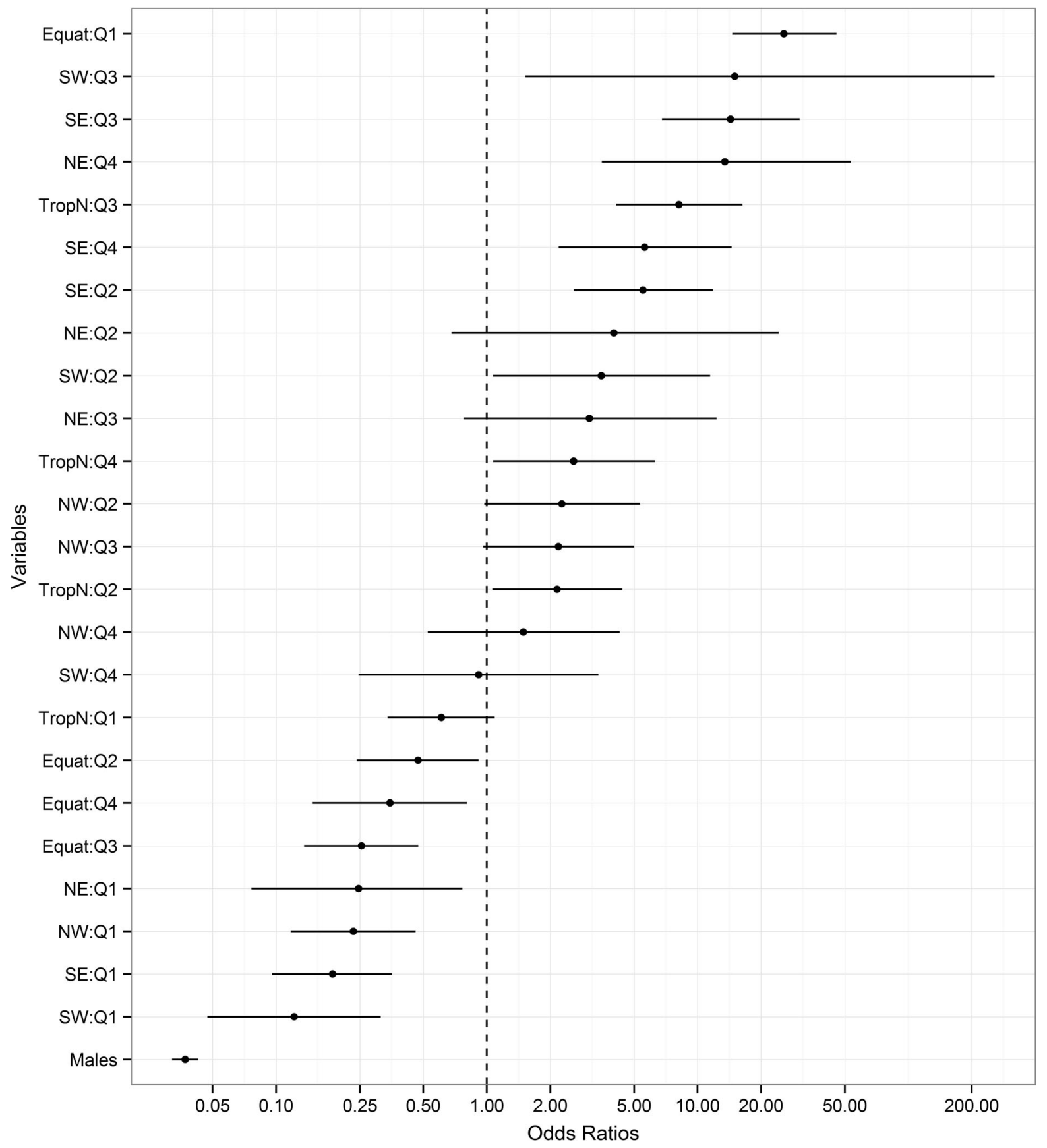

Fig. 8 Odds ratios (with $90 \%$ confidence intervals) of capturing juvenile $[<159.2 \mathrm{~cm}$ fork length (FL) for males and $<208.6 \mathrm{~cm}$ FL for females] bigeye thresher (A.

been reported (Thorpe 1997), for the northwest Pacific $357 \mathrm{~cm}$ TL for males and $422 \mathrm{~cm}$ TL for females (Liu et al. 1998), and for the northeast Atlantic $410 \mathrm{~cm}$ TL for males and $461 \mathrm{~cm}$ TL for females (Moreno and superciliosus) in each of multiple region:quarter combinations, as well as for the single effect for sex. The $\mathrm{x}$-axis is in a base 10 logarithm scale

Morón 1992). Additionally, the smallest specimens in our sample were $126 \mathrm{~cm}$ TL, slightly lower than the size at birth of 135-140 cm TL suggested by Chen et al. (1997) for the northwest Pacific, and within the 
100-140 cm TL suggested by Compagno et al. (2005) for the species globally. This indicates that the sample in our study covered most of the size range of the species. However, a very low prevalence of the smaller size classes, particularly specimens $<150 \mathrm{~cm}$ FL, was apparent in our study in most of the regions. This might be related to the fact that the fleets analyzed operate mainly in oceanic waters, while the smaller sized specimens may be occurring in other regions not covered in our study, such as more coastal areas where they would be accessible and taken by coastal fleets operating with other fishing gears such as coastal nets and longlines. Another possible hypothesis is that the lack of smaller sized specimens may be related to fishing gear selectivity, but given that bigeye threshers are born at relatively large sizes, if those smaller specimens were present in oceanic waters they would likely also be captured by pelagic longlines. As such, the hypothesis of a life history cycle with the occurrence of smaller specimens in more coastal areas and larger specimens in more oceanic waters is likely for the bigeye thresher.

As documented for many other shark species (Cortés 2000), the estimated median size at maturity was significantly higher for females $(208.6 \mathrm{~cm}$ FL, $349.1 \mathrm{~cm} \mathrm{TL}$ ) than males $(159.7 \mathrm{~cm} \mathrm{FL}, 269.8 \mathrm{~cm}$ TL). Although the number of mature females recorded in the present study was low, these values for the bigeye thresher in the Atlantic are very close to the sizes at first maturity reported by Moreno and Morón (1992) for the northeast Atlantic (from Cape São Vicente to the Ivory Coast) and west Mediterranean (340 cm TL for females and $270 \mathrm{~cm}$ TL for males, or $200.2 \mathrm{~cm}$ FL and $159.9 \mathrm{~cm}$ FL respectively). In Taiwanese waters, Chen et al. (1997) reported median sizes at maturity of $336.3 \mathrm{~cm}$ TL (estimated $198.2 \mathrm{~cm}$ FL) for females and $279 \mathrm{~cm} \mathrm{TL}$ (estimated $165.2 \mathrm{~cm}$ FL) for males, values which are just slightly lower and higher than ours for females and males, respectively. For the northwest Atlantic, Stillwell and Casey (1976) suggested $350 \mathrm{~cm}$ TL (estimated $206 \mathrm{~cm} \mathrm{FL)} \mathrm{as} \mathrm{size} \mathrm{at}$ first maturity for females and $295 \mathrm{~cm}$ TL (estimated $174.3 \mathrm{~cm}$ FL) for males, values almost identical to ours for females and a little higher for males. Significant differences between median sizes at maturity have also been reported for the common thresher (A. vulpinus) in the north Atlantic, with $216 \mathrm{~cm}$ FL for females and $188 \mathrm{~cm}$ FL for males (Natanson and Gervelis 2013) (Table 2).
The SRM of male size versus clasper length predicted that the onset of maturity in male bigeye threshers starts at ca. $122.5 \mathrm{~cm}$ FL (first breakpoint) and that all males in the population are mature at ca. $173.3 \mathrm{~cm}$ FL (second breakpoint). The fact that the median size at maturity estimated through the maturity ogive $\left(\mathrm{L}_{50}=159.2 \mathrm{~cm} F \mathrm{FL}\right)$ is included between the two breakpoints of the regression, seems to support the effectiveness of this method. Furthermore, other authors have used this approach as it provides an objective and direct estimate of the maturity stages of male elasmobranchs (using only clasper measurements) instead of relying on a subjective classification which depends on the observer's ability and may vary between different observers (Segura et al. 2013). In addition, it is a non-invasive method and can be applied to existent common fisheries data (Segura et al. 2013).

The estimated median size at maturity occurs at ca. $79 \%$ of the maximum observed size for bigeye thresher females and $61 \%$ for males. After examining 164 shark species, Cortés (2000) concluded that on average shark size-at-maturity takes place at about $75 \%$ of the maximum observed size. Thus, the values presented here follow this general trend, although our male estimation is a slightly lower than the average. Furthermore, it has been documented that the ratio of size at maturity and maximum observed length $\left(\mathrm{L}_{50} /\right.$ $\mathrm{L}_{\max }$ ) ranges from 0.5 to 0.95 for sharks, with most being between 0.65 and 0.8 (e.g. Joung and Chen 1995). The ratios obtained in the present study are comparable to the values of 0.77 and 0.67 for females and males, respectively, obtained by Moreno and Morón (1992). Stillwell and Casey (1976) reported a similar ratio to ours (0.77 vs. 0.79$)$ for females in the northwestern Atlantic but a higher value for males (0.79 vs. 0.61). In the Pacific Ocean, Chen et al. (1997) suggested an identical ratio to ours for females (0.79) and higher value for males (0.78). Following the same trend of this study, ratios of 0.8 and 0.7 were estimated in the north Atlantic for female and male shortfin mako, also a Lamniform species (Natanson et al. 2006). Joung and Chen (1995) proposed three stages of maturity based on the $\mathrm{L}_{50} / \mathrm{L}_{\max }$ ratio: $1=$ early maturity $\left(\mathrm{L}_{50} /\right.$ $\left.\mathrm{L}_{\max }<0.65\right), 2=$ standard maturity $\left(0.65<\mathrm{L}_{50}\right.$ l $\left.\mathrm{L}_{\max }<0.8\right)$, and $3=$ late maturity $\left(\mathrm{L}_{50} / \mathrm{L}_{\max }>0.8\right)$. The bigeye thresher can thus be considered to follow a standard maturity pattern, with females tending toward late maturity and males tending toward early maturity. 
Table 2 Summary of thresher shark (genus Alopias) size at maturity previously reported in the literature, with a comparison to the estimates presented in this study

\begin{tabular}{|c|c|c|c|c|}
\hline & \multicolumn{2}{|c|}{ Size at maturity $(\mathrm{TL}, \mathrm{cm})$} & \multirow[t]{2}{*}{ Region } & \multirow[t]{2}{*}{ Species } \\
\hline & Males & Females & & \\
\hline Current study ${ }^{\mathrm{a}, \mathrm{b}}$ & 269.8 & 349.1 & Atlantic & A. superciliosus \\
\hline Moreno and Morón (1992) ${ }^{\mathrm{c}}$ & 270 & 340 & NE Atlantic and Mediterranean & A. superciliosus \\
\hline Chen et al. $(1997)^{b}$ & $270-288$ & $332-341$ & NW Pacific & A. superciliosus \\
\hline Stillwell and Casey $(1976)^{\mathrm{c}}$ & 295 & 350 & NW Atlantic & A. superciliosus \\
\hline Cailliet and Bedford (1983) & 333 & $260-315$ & NE Pacific & A. vulpinus \\
\hline Smith et al. $(2008 \mathrm{a})^{\mathrm{b}}$ & $293-311$ & 303 & Pacific & A. vulpinus \\
\hline Natanson and Gervelis $(2013)^{\mathrm{a}, \mathrm{b}}$ & 333 & 386 & NW Atlantic & A. vulpinus \\
\hline Liu et al. (1999) ${ }^{b}$ & $267-276$ & $282-292$ & NW Pacific & A. pelagicus \\
\hline
\end{tabular}

\footnotetext{
${ }^{a}$ Studies that reported the estimates in fork length (FL) and were converted to total length (TL) to facilitate comparison

b Studies that reported median size at maturity

c Studies that reported size at first maturity from observational data
}

The fitted logistic-binomial GLM had a high goodness-of-fit with relatively high $\mathrm{r}^{2}$ and AUC values, and the cross-validation procedure resulted in a low misclassification error rate. Values of AUC between 0.8 and 0.9 , which is the case in the present study, are considered excellent (Hosmer and Lemeshow 2000), and as such the statistics indicate the model fits the data very well, with the model having the capacity to correctly predict the capture of juveniles in $72.0 \%$ of the cases, while at the same time it correctly predicts the capture of adults in $90.1 \%$ of the cases. The cross-validation misclassification error rate was estimated at $20.9 \%$, which also seems very reasonable, meaning that most of the time the model correctly discriminated between the capture of juvenile versus adult specimens under the analyzed variables. One advantage of this model that covered a wide area of the Atlantic is that it provides a very general overview in terms of large-scale oceanic areas, but loses some detail in specific regions and seasons. As such, this model and odds-ratios outputs should be regarded mainly as general values in the context of these large-scale oceanic areas, bearing in mind that exceptions are very likely to occur in specific and smaller-scale areas. The tropical north region seemed to differ from the remaining areas because in most seasons the odds of capturing more juveniles than adults increased significantly. Similarly, in some of the other regions there were also increased odds of capturing more juveniles, but those were dependent on specific seasons, as for example in the southwest and southwest region in the 3rd quarter.

Moreno and Morón (1992) suggested the existence of a nursery area for this species off the Southwestern Iberian Peninsula in the northeast Atlantic, based on the records of several pregnant females. After our study, we hypothesize that such an area may exist and possibly extends further south, into the tropical northeast Atlantic and equatorial waters closer to the African continent. This seems to be validated by the fact that smaller and mainly juvenile specimens tended to be captured in the tropical northeast and equatorial waters, as well as pregnant females both in mid- and late-term stages (stages 5-differentiating and 6-expecting). Additionally, the tropical northwestern Atlantic, particularly in areas closer to the Caribbean Sea and Florida, may also serve as a nursery as some very small specimens [within the range of sizes at birth described by Chen et al. (1997) and Compagno et al. (2005)] were captured, added to the fact that a previous study (Gilmore 1983) reported embryos dissected from pregnant females caught off Florida. Finally, another cluster of pregnant females was recorded in the southwest Atlantic, some close to the Rio Grande Rise and a few inside the Uruguayan EEZ, suggesting these areas may also be nurseries for this species in the south Atlantic. In the South Atlantic, a previous study by Amorim et al. (1998) had also reported the presence of pregnant females and analyzed their embryos. We can thus hypothesize that 
at least those areas may constitute a nursery for the bigeye thresher, but we cannot exclude the possibility of other nurseries in the Atlantic. In some cases we have size observations but lack reproductive data, as the observations used in this study depend on the specific objectives of the projects and programs collecting the data. Furthermore, while the geographical coverage of our study is wide, there are areas not covered and we cannot exclude the possibility of the presence of pregnant females and small juveniles in those areas.

Compared to most other shark species, threshers have very limited fecundity (Snelson et al. 2008). Both the bigeye and pelagic thresher typically have two pups per litter, although litters varying between one and four have been reported (Moreno and Morón 1992; Liu et al. 1999; Compagno 2001). In the common thresher the most common liter sizes vary between two and four but as many as seven have been reported (Moreno et al. 1989; Compagno 2001). In terms of embryo development and reproductive seasonality, the presence of the largest embryos (closer to the size at birth) in October/ November in the northeast Atlantic and in March in the southwest Atlantic, seem to suggest that birth may be taking place during late summer and autumn in both hemispheres, and corroborates what has been previously suggested for both regions, particularly by Moreno and Morón (1992) for the northeast and Amorim et al. (1998) for the southwest Atlantic. In contrast, in the Pacific Ocean Matsunaga and Yokawa (2013) reported that neonates $(<80 \mathrm{~cm}$ pre-caudal length) were caught mainly during winter and spring in an area between 10 and $15^{\circ} \mathrm{N}$, which suggests a different seasonality for the reproductive cycle and birth season in that ocean. Our study in the Atlantic Ocean was comprehensive, but we note that the capture of pregnant females of this species by pelagic longliners is relatively rare (as noted previously by Moreno and Morón 1992), and not all the sampling programs participating in this study record these observations. In some periods, namely during March in the southwest Atlantic, embryos of different sizes were recorded that included both the smallest and the largest in the region. As such, our reported embryo development and reproductive seasonality should be viewed as hypotheses requiring further investigation.

All thresher sharks are listed as "Vulnerable" globally by the IUCN and are known to have vulnerable life history parameters, resulting in a low capacity to recover even from moderate levels of exploitation (Amorim et al. 2009). The size at maturity obtained in the present study reinforces that the bigeye thresher reaches maturity at a larger size than the other species of the Alopiidae family, as stated by Smith et al. (2008a). Assuming that age at maturity is also reached at a later age (Fernandez-Carvalho et al. 2011), and considering the very limited fecundity, the reproductive potential of the bigeye thresher is suggested to be very low when compared to other sharks more prevalent in the epipelagic-oceanic areas. The distributional patterns of sizes and maturity stages in the six regions during different seasons of the year can now be used to better inform future management decisions and conservation initiatives for this species in the Atlantic Ocean.

\section{Acknowledgments}

This work was carried out as part of a cooperative study conducted by the ICCAT Shark species group. Sampling and data collection from the Portuguese fishery were obtained and funded within the scope of the EU Data Collection Framework, and as part of the projects SELECT-PAL (PROMAR Proj. 31-03-05-FEP-1), and THRESHER (FCT Proj. PTDC/MAR/109915/2009). Sampling from Uruguay was conducted by fishery observers from PNOFA. Data from Japanese longline fishery was obtained by Japan's scientific observer program managed by the Fishery Agency of Japan.The authors are grateful to all the fishery observers and longline skippers from the nations involved in this study. Joana Fernandez-Carvalho was supported by a $\mathrm{PhD}$ grant (Ref.: SFRH/BD/60624/2009) from the Portuguese Foundation for Science and Technology (FCT, Fundação para a Ciência e a Tecnologia). Rui Coelho is supported by an Investigador-FCT contract (Ref.: IF/ 00253/2014) from the Portuguese Foundation for Science and Technology (FCT, Fundação para a Ciência e Tecnologia) supported by the EU European Social Fund and the Programa Operacional Potencial Humano.

\section{References}

Akaike H (1973) Information theory and an extension of the maximum likelihood principle. In: Petrov NB, Csáki F (eds) 2nd international symposium on information theory. Akádemia Kiadó, Budapest, pp 267-281 
Amorim A, Arfelli C, Fagundes L (1998) Pelagic elasmobranchs caught by longliners off southern Brazil during 1974-97: an overview. Mar Freshw Res 49:621-632

Amorim A, Baum J, Cailliet GM, Clò S, Clarke SC, Fergusson I, Gonzalez M, Macias D, Mancini P, Mancusi C, Myers R, Reardon M, Trejo T, Vacchi M, Valenti SV (2009) Alopias superciliosus. In: IUCN 2012. IUCN Red List of Threatened Species, Version 2012.2. www.iucnredlist.org

Becker RA, Wilks AR, Brownrigg R, Minka TP (2013) maps: Draw geographical maps. R package version 2.3-6. http:// CRAN.R-project.org $/$ package $=$ maps

Berrondo L, Pons M, Forselledo R, Miller P, Domingo A (2007) Distribución espacio-temporal y composición de tallas de Alopias superciliosus y A. vulpinus observados en la flota palangrera Uruguaya en el océano Atlántico (2001-2005). Collect Vol Sci Pap ICCAT 60:566-576

Bivand R, Lewin-Koh N (2013) maptools: Tools for reading and handling spatial objects. R package version 0.8-27. http:// CRAN.R-project.org/package $=$ maptools

Cailliet GM, Bedford DW (1983) The biology of three pelagic sharks from California waters, and their emerging fisheries: a review. CalCOFI Rep XXIV:57-69

Camhi MD, Pikitch EK, Babcock EA (2008a) Methods to improve understanding of pelagic sharks: demographics, assessment, and stock structure. In: Camhi MD, Pikitch EK, Babcock EA (eds) Sharks of the open ocean: biology, fisheries and conservation. Blackwell Publishing, Oxford, pp 285-287

Camhi MD, Pikitch EK, Babcock EA (2008b) Life history and status of pelagic elasmobranchs. In: Camhi MD, Pikitch EK, Babcock EA (eds) Sharks of the open ocean: biology, fisheries and conservation. Blackwell Publishing, Oxford, pp 55-59

Castro J, Serna JM, Macías D, Mejuto J (2000) Estimaciones científicas de los desembarcos de especies asociadas realizados por la flota española de palangre de superficie en 1997 y 1998. Collect Vol Sci Pap ICCAT 51:1882-1893

Chen P, Yuan W (2006) Demographic analysis based on the growth parameter of sharks. Fish Res 78:374-379

Chen CT, Liu KM, Chang YC (1997) Reproductive biology of the bigeye thresher shark, Alopias superciliosus (Lowe, 1839) (Chondrichthyes: Alopiidae), in the northwestern Pacific. Ichthyol Res 44:227-235

Cochran WG (1954) Some methods for strengthening the common $\chi 2$ tests. Biometrics 10:417-451

Coelho R, Fernandez-Carvalho J, Lino PG, Santos MN (2012) An overview of the hooking mortality of elasmobranchs caught in a swordfish pelagic longline fishery in the Atlantic Ocean. Aquat Living Resour 25:311-319

Compagno LJV (2001) Sharks of the World. An annotated and illustrated catalogue of shark species known to date: bullhead, mackerel and carpet sharks (Heterodontiformes, Lamniformes and Orectolobiformes). FAO, Rome

Compagno LJV, Dando M, Fowler S (2005) Sharks of the World. Harper Collins, London

Conrath CL (2004) Reproductive biology. In: Musick JA, Bonfil $\mathrm{R}$ (eds) Elasmobranch fisheries management techniques. APEC Secretariat, Singapore, pp 133-164

Cortés E (2000) Life history patterns and correlations in sharks. Rev Fish Sci 8:299-344
Cortés E (2008) Comparative life history and demography of pelagic sharks. In: Camhi MD, Pikitch EK, Babcock EA (eds) Sharks of the open ocean: biology, fisheries and conservation. Blackwell Publishing, Oxford, pp 309-322

Cortés E, Arocha F, Beerkircher L, Carvalho F, Domingo A, Heupel M, Holtzhausen H, Santos MN, Ribera M, Simpfendorfer C (2010) Ecological risk assessment of pelagic sharks caught in Atlantic pelagic longline fisheries. Aquat Living Resour 23:25-34

Fawcett T (2006) An introduction to ROC analysis. Pattern Recogn Lett 27:861-874

Fernandez-Carvalho J, Coelho R, Erzini K, Santos MN (2011) Age and growth of the bigeye thresher shark, Alopias superciliosus, from the pelagic longline fisheries in the tropical northeastern Atlantic Ocean, determined by vertebral band counts. Aquat Living Resour 24:359-368

Fushiki T (2011) Estimation of prediction error by using K-fold cross-validation. Stat Comput 21:137-146

Gerritsen H (2013) mapplots: data visualisation on maps. R package version 1.4. http://CRAN.R-project.org/package= mapplots

Gilmore RG (1983) Observations on the embryos of the longfin mako, Isurus paucus, and the bigeye thresher, Alopias superciliosus. Copeia 1983:375-382

Gilmore RG (1993) Reproductive biology of lamnoid sharks. Environ Biol Fishes 38:95-114

Gruber SH, Compagno LJV (1981) Taxonomic status and biology of the bigeye thresher Alopias superciliosus. Fish Bull 79:617-640

Hosmer DW, Lemeshow S (2000) Applied logistic regression, 2nd edn. Wiley, New York

ICCAT (2006-2013) ICCAT manual. International Commission for the Conservation of Atlantic Tunas. ICCAT Publications (on-line). Updated 2013. http://www.iccat.int/ en/ICCATManual.htm

ICCAT (2013) Report of the inter-sessional meeting of the sharks species group. Mindelo, Cape Verde, 81 pp. 8-12 April 2013

Joung SJ, Chen CT (1995) Reproduction in the sandbar shark, Carcharhinus plumbeus, in the waters off northeastern Taiwan. Copeia 1995:659-665

Levene H (1960) Robust tests for equality of variances. In: Olkin I, Ghurye SG, Hoeffding W, Madow WG, Mann HB (eds) Contributions to probability and statistics: essays in honor of harold hotelling. Stanford University Press, Redwood City, pp 278-292

Lilliefors HW (1967) On the Kolmogorov-Smirnov test for normality with mean and variance unknown. J Am Statist Assoc 62:399-402

Liu KM, Chiang PJ, Chen CT (1998) Age and growth estimates of the bigeye tresher shark, Alopias superciliosus, in northeastern Taiwan waters. Fish Bull 96:482-491

Liu KM, Chen CT, Liao TH, Joung SJ (1999) Age, growth, and reproduction of the pelagic thresher shark Alopias pelagicus in the northwestern Pacific. Copeia 1999:68-74

Mancini P, Amorim A (2006) Embryos of common thresher shark Alopias vulpinus in southern Brazil, South Atlantic Ocean. J Fish Biol 69:318-321

Manly B (2007) Randomization bootstrap and Monte Carlo methods in biology, 3rd edn. Chapman \& Hall, New York 
Matsunaga H, Yokawa K (2013) Distribution and ecology of bigeye thresher Alopias superciliosus in the Pacific Ocean. Fish Sci 79:737-748

Mejuto J (1985) Associated catches of sharks, Prionace glauca, Isurus oxyrinchus, and Lamna nasus, with $\mathrm{NW}$ and $\mathrm{N}$ Spanish swordfish fishery, in 1984. International Council for the Exploration of the Sea. C.M. 1985/H: 42, 16 pp

Mejuto J, Garcés AG (1984) Shortfin mako, Isurus oxyrinchus, and porbeagle, Lamna nasus, associated with longline swordfish fishery in $\mathrm{NW}$ and $\mathrm{N}$ Spain. International Council for the Exploration of the Sea. C.M. 1984/G: 72, $10 \mathrm{pp}$

Mejuto J, García-Cortés B, Ramos-Cartelle A, Serna JM (2009) Scientific estimations of by-catch landed by the Spanish surface longline fleet targeting swordfish (Xiphias gladius) in the Atlantic Ocean with special reference to the years 2005 and 2006. Collect Vol Sci Pap ICCAT 64:2455-2468

Mizuno K, Okazaki M, Miyabe N (1998) Fluctuation of longline shortening rate and its effect on underwater longline shape. Bull Nat Res Inst Far Seas Fish 35:155-164

Moreno JA, Morón J (1992) Reproductive biology of the bigeye thresher shark, Alopias superciliosus (Lowe, 1839). Aust J Mar Freshw Res 43:77-86

Moreno JA, Parajuá JI, Morón J (1989) Biología reproductiva y fenología de Alopias vulpinus (Bonnaterre, 1788) (Lamniformes: Alopiidae) en el Atlántico nor-oriental y Mediterráneo occidental. Sci Mar 53:37-46

Muggeo VMR (2003) Estimating regression models with unknown break-points. Stat Med 22:3055-3071

Nagelkerke N (1991) A note on a general definition of the coefficient of determination. Biometrika 78:691-692

Natanson LJ, Gervelis BJ (2013) The reproductive biology of the common thresher shark in the western north Atlantic Ocean. Trans Am Fish Soc 142:1546-1562

Natanson LJ, Kohler NE, Ardizzone D, Cailliet GM, Wintner SP, Mollet HF (2006) Validated age and growth estimates for the shortfin mako, Isurus oxyrinchus, in the North Atlantic Ocean. Environ Biol Fish 77:367-383

Palma C, Gallego JL (2010) Estimation of the overall longline effort distribution (month and 5 by 5 degree squares) in the ICCAT area, between 1950 and 2007. Collect Vol Sci Pap ICCAT 65:2282-2296

Pikitch EK, Camhi MD, Babcock EA (2008) Introduction to sharks of the open ocean. In: Camhi MD, Pikitch EK, Babcock EA (eds) Sharks of the open ocean: biology, fisheries and conservation. Blackwell Publishing, Oxford, pp 3-13

Romero-Caicedo A (2007) Aspectos reproductivos del tiburón rabón Alopias pelagicus (Nakamura, 1935) en Manta,
Ecuador. In: Martínez-Ortíz J, Galván-Magaña F (eds) Tiburones en el Ecuador: Casos de estudio/Sharks in Ecuador: case studies. EPESPO - PMRC, Manta, Ecuador, pp 28-34

Segura AM, Milessi AC, Vogler R, Galvan-Magana F, Muggeo V (2013) The determination of maturity stages in male elasmobranchs (Chondrichthyes) using a segmented regression of clasper length on total length. Can J Fish Aquat Sci 70:830-833

Siegel S, Castellan NJ (1988) Non parametric statistics for the behavioural sciences. MacGraw Hill, New York

Simpfendorfer CA (2004) Demographic models: life tables, matrix models and rebound potential. In: Musick JA, Bonfil R (eds) Elasmobranch fisheries management techniques. APEC Secretariat, Singapore, pp 133-164

Smith SE, Rasmussen RC, Ramon DA, Cailliet GM (2008a) The biology and ecology of thresher sharks (Alopiidae). In: Camhi MD, Pikitch EK, Babcock EA (eds) Sharks of the open ocean: biology, fisheries and conservation. Blackwell Publishing, Oxford, pp 60-68

Smith SE, Au DW, Show C (2008b) Intrinsic rates of increase in pelagic elasmobranchs. In: Camhi MD, Pikitch EK, Babcock EA (eds) Sharks of the open ocean: biology, fisheries and conservation. Blackwell Publishing, Oxford, pp 288-297

Snelson FF Jr, Burgess GH, Roman BL (2008) The reproductive biology of pelagic elasmobranchs. In: Camhi MD, Pikitch EK, Babcock EA (eds) Sharks of the open ocean: biology, fisheries and conservation. Blackwell Publishing, Oxford, pp 24-53

Stehmann MFW (2002) Proposal of a maturity stages scale for oviparous and viviparous cartilaginous fishes (Pisces, Chondrichthyes). Arch Fish Mar Res 50:23-48

Stillwell CE, Casey JG (1976) Observations on the bigeye thresher shark, Alopias superciliosus, in the western north Atlantic. Fish Bull 74:221-225

R Core Team (2013) R: a language and environment for statistical computing. R Foundation for Statistical Computing, Vienna, Austria. http://www.R-project.org

Thorpe T (1997) First occurrence and new length record for bigeye thresher in North-East Atlantic. J Fish Biol 50:222-224

Warnes GR, Bolker B, Lumley T, Johnson RC (2012) gmodels: Various R programming tools for model fitting. R package version 2.15.3. http://CRAN.R-project.org/package= gmodels

Wickham H (2009) ggplot2: Elegant graphics for data analysis. Springer, New York 